\title{
Increased Production of Tumor Necrosis Factor- $\alpha$ by Glial Cells Exposed to Simulated Ischemia or Elevated Hydrostatic Pressure Induces Apoptosis in Cocultured Retinal Ganglion Cells
}

\author{
Gülgün Tezel and Martin B. Wax \\ Department of Ophthalmology and Visual Sciences, Washington University School of Medicine, St. Louis, Missouri 63110
}

\begin{abstract}
Although glial cells in the optic nerve head undergo a reactivation process in glaucoma, the role of glial cells during glaucomatous neurodegeneration of retinal ganglion cells is unknown. Using a coculture system in which retinal ganglion cells and glial cells are grown on different layers but share the same culture medium, we studied the influences of glial cells on survival of retinal ganglion cells after exposure to different stress conditions typified by simulated ischemia and elevated hydrostatic pressure. After the exposure to these stressors, we observed that glial cells secreted tumor necrosis factor- $\alpha$ (TNF- $\alpha$ ) as well as other noxious agents such as nitric oxide into the coculture media and facilitated the apoptotic death of retinal ganglion cells as assessed by morphology, terminal deoxynucleotidyl transferase-mediated dUTP nick end labeling, and caspase activity. The glial origin of these
\end{abstract}

noxious effects was confirmed by passive transfer experiments. Furthermore, retinal ganglion cell apoptosis was attenuated $\sim 66 \%$ by a neutralizing antibody against TNF- $\alpha$ and $50 \%$ by a selective inhibitor of inducible nitric oxide synthase (1400W). Because elevated intraocular pressure and ischemia are two prominent stress factors identified in the eyes of patients with glaucoma, these findings reveal a novel glia-initiated pathogenic mechanism for retinal ganglion cell death in glaucoma. In addition, these findings suggest that the inhibition of TNF- $\alpha$ that is released by reactivated glial cells may provide a novel therapeutic target for neuroprotection in the treatment of glaucomatous optic neuropathy.

Key words: apoptosis; glaucoma; glia; nitric oxide; retinal ganglion cell; tumor necrosis factor- $\alpha$
During development and maintenance of the nervous system there exists a complex interdependency between neurons and glial cells. The glial cells maintain normal functioning of the nervous system both by controlling the extracellular environment and by supplying metabolites and growth factors. However, recent evidence challenges the view that glial cells are purely neuroprotective and rather suggests that they could participate in damaging neurons. For example, after focal cerebral ischemia or during the course of neurodegenerative diseases or trauma, reactive astrocytes as well as microglia within the CNS produce cytokines, reactive oxygen species, and nitric oxide (NO), which are implicated as mediators of tissue injury (Hewett et al., 1994; Dugan et al., 1995; Ridet et al., 1997; Vandenberghe et al., 1998; Viviani et al., 1998; Raivich et al., 1999).

The astrocytes located at the optic nerve head undergo a reactivation process in glaucoma (Hernandez and Pena, 1997). In glaucomatous optic neuropathy, apoptosis is implicated in the death of retinal ganglion cells (Quigley et al., 1995), but the precise pathogenic mechanisms leading to apoptotic cell death are unknown. Although the relationship of glial reactivation to neurodegeneration in glaucoma has not been established, increased production of some neurotoxic substances by optic nerve head astrocytes has been identified in glaucomatous eyes. For example, increased production of nitric oxide synthase (NOS; Neufeld et al., 1997) and tumor necrosis factor- $\alpha$ (TNF- $\alpha$; Yan et al., 2000) has been described in the glaucomatous optic nerve head. In addition, expression of the inducible isoform of NOS (iNOS) and TNF- $\alpha$ by chemically reactivated retinal glial cells has been observed in rat models of hereditary retinal diseases (Cotinet et al., 1997; de

Received June 19, 2000; revised Aug. 14, 2000; accepted Sept. 11, 2000.

This study was supported in part by The Glaucoma Foundation (New York, NY; to G.T.), National Eye Institute Grant EY12314 (Bethesda, MD), Glaucoma Research Foundation (San Francisco, CA; to M.B.W.), and an unrestricted grant to Washington University School of Medicine, Department of Ophthalmology and Visual Sciences, from Research to Prevent Blindness (New York, NY).

Correspondence should be addressed to Dr. Martin B. Wax, Department of Ophthalmology and Visual Sciences, Washington University School of Medicine, Box 8096, 660 South Euclid Avenue, St. Louis, MO 63110. E-mail: Wax@vision.wustl.edu. Copyright (c) 2000 Society for Neuroscience 0270-6474/00/208693-08 $\$ 15.00 / 0$
Kozak et al., 1997; Goureau et al., 1999). Therefore, we hypothesize that retinal astroglial reactivation may lead to the increased production of neurotoxic substances and thereby participate in neuronal damage in glaucoma.

Although neuron-glia interactions have been examined in experimental models of degenerative diseases of the CNS, there is no direct evidence suggesting that glial cells are harmful to the survival of retinal ganglion cells. Using a coculture system, we studied the effects of glial cells on the survival of retinal ganglion cells after exposure to different stress conditions. This coculture system provides a good model to study neuron-glia interactions because it permits quantitative assessment of the effects of different stimuli on neuronal and glial cells separately. During these experiments we used elevated hydrostatic pressure and simulated ischemia as stress conditions, because elevated intraocular pressure and ischemia are common stress factors identified in glaucomatous eyes, which are thought to facilitate retinal ganglion cell apoptosis (Hart et al., 1979; Quigley et al., 1980; Hayreh, 1985).

Here we present novel evidence that elevated hydrostatic pressure as well as simulated ischemia can initiate the apoptotic cell death cascade in retinal ganglion cells, mainly because of the reactivity of glial cells in response to these stressors. Apoptosispromoting substances, including $\mathrm{TNF}-\alpha$ secreted by reactivated glial cells after exposure to stress, contribute directly to neuronal cytotoxicity.

\section{MATERIALS AND METHODS}

Retinal ganglion cell cultures. Primary cultures of retinal ganglion cells were derived from newborn rat retinas, using a protocol similar to that recently described (Tezel et al., 1999). All experiments were performed in accordance with the Association for Research in Vision and Ophthalmology (ARVO) Statement for the Use of Animals in Ophthalmic and Vision Research and were approved by The Animal Studies Committee of Washington University. Sprague Dawley rats (5-7 d old) were anesthetized, and their eyes were enucleated. The eyes were rinsed with $\mathrm{CO}_{2}$-independent culture medium (Life Technologies, Grand Island, NY), and retinas were dissected mechanically under a microscope. To prepare retinal cell suspensions, we dissociated tissues in Eagle's MEM containing $20 \mathrm{U} / \mathrm{ml}$ papain, $1 \mathrm{~mm}$ L-cysteine, $0.5 \mathrm{~mm}$ EDTA, and $0.005 \%$ DNase (Worthington, Lakewood, $\mathrm{NJ}$ ) at $37^{\circ} \mathrm{C}$ for $40 \mathrm{~min}$. Then the retinas were rinsed in an inhibitor solution containing Eagle's MEM, $0.2 \%$ ovomucoid (US Biolog- 
ical, Swampscott, MA), $0.04 \%$ DNase, and $0.1 \%$ bovine serum albumin (Sigma, St. Louis, MO). At the end of the treatment period the tissues were triturated through a $1 \mathrm{ml}$ plastic pipette to yield a suspension of single cells. The retinal cells were spun at $400 \times g$ for $10 \mathrm{~min}$, resuspended in Eagle's MEM containing $0.05 \%$ bovine serum albumin, and incubated in a tissue culture incubator until their immediate use for subsequent separation by immunomagnetic selection.

Immunomagnetic selection of the retinal ganglion cells was performed by using magnetic, $2.8 \pm 0.2 \mu \mathrm{m}$ diameter, polystyrene beads coated with biotinylated rat monoclonal antibody against mouse $\mathrm{IgG}_{1}$ (Dynal, Oslo, Norway) in a two-step process. In the first step, after a washing with PBS solution containing $0.1 \%$ bovine serum albumin, $1 \times 10^{7}$ beads $/ \mathrm{ml}$ were added to the monoclonal antibody against macrophage surface antigens $(100 \mu \mathrm{g} / \mathrm{ml}$; Sigma). After incubation at room temperature on a rotator for $30 \mathrm{~min}$, the beads were washed with a specially designed magnet (Dynal) Coated beats were incubated with retinal cell suspension with gentle rotation for $15 \mathrm{~min}$ and then removed from the cell suspension to remove the bound macrophages. As a second step, fresh magnetic beads were added to monoclonal antibody $\left(\operatorname{IgG}_{1}\right)$ specific to Thy-1.1 (Chemicon, Temecula, CA) to obtain a final concentration of $100 \mu \mathrm{g} / \mathrm{ml}$. After incubation at room temperature for $30 \mathrm{~min}$ and washing, the coated beads were incubated with the macrophage-depleted retinal cell suspension for $15 \mathrm{~min}$. Because the monoclonal antibody was attached to beads via streptavidin and a DNA linker, the attached cells were separated from the beads by incubation with DNase-releasing buffer $(50 \mathrm{U} / \mu \mathrm{l})$ at $37^{\circ} \mathrm{C}$ for $15 \mathrm{~min}$. Then the cells were seeded on extracellular matrix-coated 24-well plates (Fisher Scientific, Pittsburgh, PA) at a density of $4 \times 10^{4}$ cells/well and were cocultured with glial cells. Cultures were incubated in a tissue culture incubator with a humidified atmosphere of $5 \% \mathrm{CO}_{2} / 95 \%$ air at $37^{\circ} \mathrm{C}$.

A retinal glial cell line was prepared with the retinal cells that were depleted for microglial and ganglion cells by following the magnetic selection process described above. After the loss of residual neuronal cells by two or three cycles of replating, these cultures contained essentially glial cells as previously described, which were identified as astrocytes and Müller glial cells, as presented in Results. The retinal glial cells were seeded on tissue culture inserts (Fisher Scientific) at a density of $3 \times 10^{4}$ cells/well and placed in the wells in which the retinal ganglion cells were seeded. These inserts contain polyethylene terephthalate membrane with $0.4 \mu \mathrm{m}$ pore size and allow for the transport of secreted molecules while preventing cell migration.

The serum-free culture medium was prepared by using B27supplemented Neurobasal (Life Technologies) as previously described (Barres et al., 1988; Brewer et al., 1993). The medium also contained (in $\mu \mathrm{g} / \mathrm{ml}) 100$ bovine serum albumin, 5 insulin, 16 putrescine, and 100 transferrin; $1 \mathrm{~mm}$ pyruvate, $1 \mathrm{~mm}$ glutamine; (in $\mathrm{ng} / \mathrm{ml}$ ) 60 progesterone, 40 sodium selenite, 30 triiodo-thyronine, $50 \mathrm{BDNF}, 20 \mathrm{CNTF}$, and 10 bFGF; $5 \mu \mathrm{M}$ forskolin, $100 \mu \mathrm{M}$ inosine, and antibiotics (Jo et al., 1999). All supplements were purchased from Sigma.

Retrograde labeling of retinal ganglion cells. Under general anesthesia that used a mixture of $80 \mathrm{mg} / \mathrm{kg}$ ketamine (Fort Dodge Laboratories, Fort Dodge, IA) and $12 \mathrm{mg} / \mathrm{kg}$ xylazine (Butler, Columbus, $\mathrm{OH}$ ) given intraperitoneally and with immobilization of the rats in a stereotaxic apparatus, bilateral microinjections of Fluoro-Gold $(1.5 \mu \mathrm{l}$ of a $5 \%$ solution of Fluoro-Gold in 0.9\% sodium chloride; Fluorochrome, Englewood, $\mathrm{CO}$ ) into the superior colliculi were performed according to the previously described methods (Selles-Navarro et al., 1996). One week after FluoroGold application the retinas were dissected and dissociated. After a selection of retinal ganglion cells via the immunomagnetic method, selected and unselected cells were examined by flow cytometry after double immunolabeling of Fluoro-Gold and Thy-1.1.

Flow cytometry. Retinal cells were fixed with $2 \%$ paraformaldehyde solution for $20 \mathrm{~min}$ at room temperature. After centrifuge and resuspension of the cells, they were permeabilized in Triton X-100 $(0.4 \%$ in PBS solution) for $30 \mathrm{~min}$. Washed cells then were incubated with a mixture of rabbit antibody against Fluoro-Gold (Fluorochrome) and mouse antibody against Thy-1.1 at a 1:100 dilution for $30 \mathrm{~min}$. After washing, the cells were incubated with a mixture of FITC-and Cy3-conjugated secondary antibodies (Sigma) for another $30 \mathrm{~min}$. Then the cells were washed, resuspended at $10^{6}$ cells $/ \mathrm{ml}$, and counted with a FACScan flow cytometer/ CELLQuest software system (Becton Dickinson, San Jose, CA).

Study design. The retinal ganglion cells exhibiting contact of the neuritic processes and glial cells that had been grown to approximate confluence were incubated under stress conditions or normal conditions. For simulated ischemia the cells were exposed to reduced oxygen tensions in a medium lacking glucose. Hypoxia was maintained by placing the cultures in a dedicated culture incubator with a controlled flow of $95 \% \mathrm{~N}_{2} / 5 \% \mathrm{CO}_{2}$. A closed pressurized chamber equipped with a manometer was used to expose the cells to elevated hydrostatic pressure. The pressure was elevated to $50 \mathrm{mmHg}$. The chamber was placed in a regular tissue culture incubator at $37^{\circ} \mathrm{C}$. To examine the time course of cellular responses, we maintained the simulated ischemia or elevated pressure for $6,12,24,48$, or $72 \mathrm{hr}$. Control cells from an identical passage of cells were incubated simultaneously in a regular tissue culture incubator at $95 \%$ air $/ 5 \% \mathrm{CO}_{2}$ at $37^{\circ} \mathrm{C}$. To examine glial sources of noxious insults on retinal ganglion cells, we collected conditioned medium from glial cells that were cultured alone after their incubation in the presence or absence of stress conditions for 72 hr. Retinal ganglion cells that were cultured alone then were incubated with the conditioned medium of glial cells for $24 \mathrm{hr}$.

In addition, to examine the role of TNF- $\alpha$ and $\mathrm{NO}$ on cell survival, we performed incubations under stress conditions in the presence or absence of specific inhibitors. A neutralizing antibody (AF510NA) was used to inhibit TNF- $\alpha$ activity (R\&D Systems, Minneapolis, MN). The ability of this antibody to neutralize the bioactivity of recombinant rat TNF- $\alpha$ in the L-929 cell line in the presence of actinomycin D revealed that the neutralization dose $_{50}$ was $\sim 0.3-0.9 \mu \mathrm{g} / \mathrm{ml}$ in the presence of $0.025 \mathrm{ng} / \mathrm{ml}$ of recombinant rat TNF- $\alpha$. The neutralizing antibody of TNF- $\alpha$ activity was neuroprotective in in vitro or in vivo experiments (Barone et al., 1997; Lavine et al., 1998; Downen et al., 1999). In addition, $[N-(3-$ [aminomethyl]benzyl)acetamidine dihydrochloride] (1400W; Alexis, San Diego, CA), a selective inhibitor of iNOS, was used to inhibit inducible synthesis of NO (Garvey et al., 1997). We used $10 \mu \mathrm{g} / \mathrm{ml}$ of the neutralizing antibody of TNF- $\alpha$ and $2.5 \mu \mathrm{M}$ of the iNOS inhibitor $1400 \mathrm{~W}$, because these were optimum conditions to inhibit TNF- $\alpha$ and iNOS, respectively, in our cocultures on the basis of concentration-response experiments (data not shown). At the end of the incubation period the cells were subjected immediately to the experiments described below, which were repeated at least three times for each condition.

The viability of the cells was determined with the Live/Dead Kit (Molecular Probes, Eugene, OR), which contains calcein-AM and ethidium homodimer (Haugland and Larison, 1994). Calcein-AM is a cell-permeable fluorogenic esterase substrate. The kit relies on the intracellular esterase activity within living cells to hydrolyze calcein-AM to a green fluorescent product, calcein. In dead cells ethidium can pass easily through the compromised plasma and nuclear membranes and attach to the DNA, yielding red fluorescence. Cells were counted in at least 10 random fields of each well at $200 \times$ magnification $(\sim 150$ ganglion cell per well) with a fluorescence microscope (Olympus, Tokyo, Japan). The viability of the cells was expressed as the average ratio of esterase $(+)$ cells to the total number of cells multiplied by 100 .

Morphological analysis of apoptosis. An in situ cell death detection kit (Boehringer Mannheim, Mannheim, Germany) was used to identify the apoptotic cells by the terminal deoxynucleotidyl transferase-mediated dUTP nick end labeling (TUNEL) technique (Gavrieli et al., 1992). Briefly, after fixation, permeabilization, and blocking steps the air-dried cells were incubated with a mixture of fluorescein-labeled nucleotides and terminal deoxynucleotidyl transferase for $1 \mathrm{hr}$. Terminal deoxynucleotidyl transferase catalyzes the polymerization of labeled nucleotides to free $3^{\prime}-\mathrm{OH}$ terminals of DNA fragments. Cells incubated with fluoresceinlabeled nucleotide mixture without the presence of terminal deoxynucleotidyl transferase served as a negative control. Cells previously treated with DNase I $(1 \mathrm{mg} / \mathrm{ml})$ to induce breaks in the DNA strands served as a positive control. TUNEL-positive cells were counted in triplicate wells under a fluorescence microscope, and the percentage of apoptosis was calculated by using the total number of cells in these wells.

Western blotting. After the cells were washed with PBS solution, they were lysed in sample buffer (1\% SDS, $100 \mathrm{~mm}$ dTT, $60 \mathrm{~mm}$ Tris, pH 6.8, and $0.001 \%$ bromophenol blue). Protein concentrations were determined via the bicinchoninic acid (BCA) method (Sigma). The samples were boiled for $5 \mathrm{~min}$ before they were subjected to electrophoresis.

Samples were separated by electrophoresis in 10-15\% SDS polyacrylamide gels at $160 \mathrm{~V}$ for $1 \mathrm{hr}$ and electrophoretically transferred to polyvinylidene fluoride membranes (Millipore, Marlboro, MA) via a semi-dry transfer system (Bio-Rad, Hercules, CA). After transfer the membranes were blocked in a buffer $(50 \mathrm{~mm}$ Tris $\mathrm{HCl}, 154 \mathrm{~mm} \mathrm{NaCl}$, and $0.1 \%$ Tween-20, $\mathrm{pH} 7.5$ ) containing $5 \%$ nonfat dry milk for $1 \mathrm{hr}$ and then overnight in the same buffer containing a dilution of primary antibody and sodium azide. Primary antibodies were monoclonal antibodies to TNF- $\alpha$ (R\&D Systems), isotypes of NOS (neuronal NOS and iNOS; Transduction Laboratories, Lexington, KY), caspase-8, or polyclonal antibody to caspase-3 (PharMingen, San Diego, CA); they were used at a dilution of 1:1000. After several washes and a second blocking for $20 \mathrm{~min}$, the membranes were incubated with a dilution of secondary antibodies conjugated with horseradish peroxidase (Fisher Scientific) at 1:2000 for $1 \mathrm{hr}$. Immunoreactive bands were visualized by enhanced chemiluminescence with the use of commercial reagents (Amersham Life Science, Arlington Heights, IL).

Examination of caspase activity. Caspase-3-like activity was examined in situ after staining with Phiphilux- $\mathrm{G}_{6} \mathrm{D}_{2}$ (Alexis, San Diego, CA). Phiphilux- $G_{6} D_{2}$ is a cell-permeable fluorogenic substrate that is cleaved to produce rhodamine molecules and that can be used to detect caspase-3-like activity in living cells (Finucane et al., 1999). For staining, the washed cells were incubated with a substrate solution of $10 \mu \mathrm{M}$ for $20 \mathrm{~min}$ at $37^{\circ} \mathrm{C}$. Rhodamine fluorescence was visualized under a fluorescence microscope. In addition, caspase-3-like protease activity was measured in a fluorometric assay by measuring the extent of cleavage of the fluorometric peptide substrate as previously described (Cheng et al., 1998; Tezel and Wax, 1999). Briefly, cell lysates were incubated with Ac-Asp-Glu-Val-Asp7-amino-4-trifluoro-methyl coumarin (Ac-DEVD-AMC) fluorometric substrate $(50 \mu \mathrm{M})$. Positive controls included purified recombinant caspase-3 $(0.1 \mu \mathrm{g}$; Upstate Biotechnology, Lake Placid, NY). Fluorescence was measured at an excitation wavelength of $360 \mathrm{~nm}$ and an emission wavelength of $460 \mathrm{~nm}$ in a fluorescent plate reader at different time points up to $180 \mathrm{~min}$. The protease activity was expressed as picomoles of substrate 
per milligram of protein per minute as calculated by using the linear range of the assay.

Immunocytochemistry. Cells were washed in PBS solution and fixed with $4 \%$ paraformaldehyde solution for $30 \mathrm{~min}$ at room temperature. After washing, they were permeabilized with $0.1 \%$ Triton X-100 in $0.1 \%$ sodium citrate solution on ice for $4 \mathrm{~min}$. Then the cells were treated with $3 \%$ bovine serum albumin for $30 \mathrm{~min}$ to block the nonspecific binding sites. Triplicate wells were incubated with monoclonal antibodies against TNF- $\alpha$ (R\&D Systems) or isotypes of NOS (neuronal NOS and iNOS; Transduction Laboratories) at $37^{\circ} \mathrm{C}$ for $2 \mathrm{hr}$. Next the samples were washed and incubated with the appropriate second antibodies conjugated with $\mathrm{Cy} 3$ (Sigma). After washing, they were examined with a fluorescence microscope.

For examination of the purity of cultures the cells were doubleimmunolabeled with specific cell markers. For double immunofluorescence labeling after the fixation, permeabilization, and blocking steps, the cultures were incubated with a mixture of two antibodies (one rabbit and one mouse antibody) against Thy-1.1, neurofilament protein, glial fibrillary acidic protein, or S-100 protein (Sigma) at 1:100 dilution for $30 \mathrm{~min}$. After being washed, the cells were incubated with a mixture of Cy3- and FITC-conjugated secondary antibodies (Sigma) for another $30 \mathrm{~min}$. Negative controls were performed by replacing the primary antibody with nonimmune serum or by incubating the cells with each primary antibody, followed by the inappropriate secondary antibody to determine that each secondary antibody was specific to the species it was made against. Then the cultures were examined with a fluorescence microscope.

Enzyme-linked immunosorbent assay (ELISA). We used a kit to measure TNF- $\alpha$ levels in conditioned medium by quantitative sandwich ELISA technique (R\&D Systems). Conditioned medium was incubated in microwells coated with monoclonal antibody specific for rat TNF- $\alpha$. After a wash, horseradish peroxidase-conjugated polyclonal antibody specific for rat TNF- $\alpha$ was added to the wells. After another wash, a substrate solution containing hydrogen peroxide and tetramethylbenzidine was added. The enzyme reaction was terminated by the addition of hydrochloric acid solution, and absorbance was measured at $450 \mathrm{~nm}$. Using a standard curve prepared from seven dilutions of recombinant rat TNF- $\alpha$, we calculated the concentrations of TNF- $\alpha$ in conditioned medium. The sensitivity was $<5 \mathrm{pg} / \mathrm{ml}$.

Colorimetric assay. To measure breakdown products of NO in conditioned medium, we used a colorimetric assay kit (R\&D Systems). This assay determined NO on the basis of the enzymatic conversion of nitrate to nitrite by nitrate reductase. The reaction was followed by a colorimetric detection of nitrite as an azo dye product of the Griess reaction. As an additional step, lactate dehydrogenase and pyruvic acid were used before color formation to oxidize the excess of NADPH because NADPH, an essential cofactor for the function of NOS enzyme, interferes with the chemistry of Griess reagents. Because the relative levels of nitrate and nitrite can vary substantially, depending on the ambient conditions and redox state of the biological fluids, for the most accurate determination of total NO production both the nitrate and nitrite levels were measured. The absorbance was read at $540 \mathrm{~nm}$, and the concentrations of breakdown products of NO were calculated by using a standard curve. The sensitivity of the nitrite assay was $<0.22 \mu \mathrm{mol} / \mathrm{l}$, and the sensitivity of the nitrate assay was $<0.54 \mu \mathrm{mol} / 1$.

\section{RESULTS}

\section{Cell morphology and viability}

Retinal ganglion cells were identified on the basis of retrograde labeling with Fluoro-Gold, morphology, and expression of cell markers. After retrograde labeling with Fluoro-Gold and the selection of retinal ganglion cells by an immunomagnetic separation method, the cells were immunolabeled by antibodies against Fluoro-Gold and Thy-1.1. Using flow cytometry, we observed that the immunolabeling by Fluoro-Gold and Thy-1.1 antibodies was colocalized in $>90 \%$ of these cells; $>95 \%$ of the cells were positive for Thy-1.1 (Fig. 1A). Cells unselected by sorting were negative for both Fluoro-Gold and Thy-1.1 (Fig. 1B).

Cultured retinal ganglion cells had round or oval cell bodies with a diameter of $10-20 \mu \mathrm{m}$, a phase-bright appearance, and branched neurites of uniform caliber and varying length (Fig. $1 C$ ), as previously identified (Barres et al., 1988). In addition, the purity of cultured retinal cells was examined by using immunolabeling for specific markers. The retinal ganglion cells were homogenously positive for Thy-1.1 and neurofilament protein, but negative for glial markers. Glial cells were homogenously labeled for glial fibrillary acidic protein, selectively labeled for S-100, but unlabeled for neuronal markers (Fig. 1).
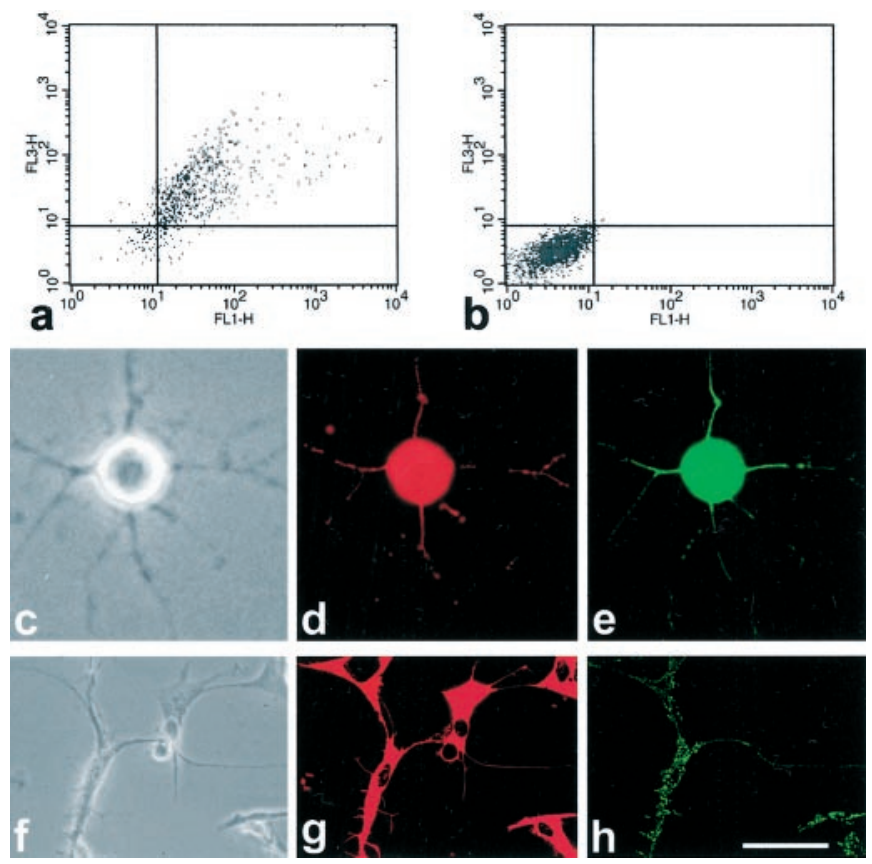

Figure 1. Cultured retinal cells. After retrograde labeling by Fluoro-Gold and the selection of retinal ganglion cells by the use of an immunomagnetic separation method, the selected cells were immunolabeled with antibodies against Fluoro-Gold and Thy-1.1; they were examined with flow cytometry. $A$, Immunolabeling with Fluoro-Gold $(F L 1-H)$ and Thy-1.1 $(F L 3-H)$ antibodies was colocalized in $>90 \%$ of these cells; $>95 \%$ of these cells were positive for Thy-1.1. B, Unselected cells were negative for both FluoroGold $(F L 1-H)$ and Thy-1.1 (FL3-H). Cultured retinal ganglion cells had round or oval cell bodies with a diameter of $10-20 \mu \mathrm{m}$, phase-bright appearance, and branched neuritis of uniform caliber and varying length. $C$, A retinal ganglion cell derived from newborn rat retina. $D$, Fluorescence microscope image of the retinal ganglion cell shown in $C$ after labeling for neurofilament protein. $E$, Fluorescence microscope image of the retinal ganglion cell shown in $C$ after labeling for Thy-1.1. $F$, Glial cells derived from newborn rat retina. $G$, Fluorescence microscope image of the retinal glial cells shown in $F$ after labeling for glial fibrillary acidic protein. $H$, Fluorescence microscope image of the retinal glial cells shown in $F$ after labeling for S-100. Scale bars: $C-E, 20 \mu \mathrm{m} ; F-H, 60 \mu \mathrm{m}$.

At the beginning of the incubation of the cocultures under stress conditions, the percentage of living retinal ganglion cells and glial cells was $96.69 \pm 1.6$ and $97.84 \pm 1.9 \%$, respectively. The cell viability decreased to $69.69 \pm 2.0$ and $76.64 \pm 1.9 \%$ in retinal ganglion cells after $72 \mathrm{hr}$ of incubation in the presence of simulated ischemia or elevated hydrostatic pressure, respectively. However, the viability of glial cells was $96.24 \pm 2.1 \%$ at the end of incubation period under either simulated ischemia or elevated hydrostatic pressure.

\section{Induction of apoptosis in retinal ganglion cells in cocultures exposed to simulated ischemia or elevated hydrostatic pressure}

Apoptosis was induced in retinal ganglion cells after the incubation of the cocultures in the presence of simulated ischemia or elevated hydrostatic pressure for as long as $72 \mathrm{hr}$. Specific morphological changes of apoptotic cell death included cell body shrinkage and compaction of the nucleus (Fig. $2 A-C$ ). In addition, apoptotic cell death was examined via the TUNEL technique. The apoptotic retinal ganglion cells exhibited bright labeling of fragmented nuclear DNA by TUNEL (Fig. $2 D-F$ ). However, there was no evidence of apoptosis in glial cells in the cocultures that were incubated under stress conditions by either morphological examination or TUNEL technique (Fig. $2 G-L$ ).

Quantitative examination of apoptotic cell death after incubation under stress conditions revealed that the percentage of positive TUNEL was approximately three times greater in retinal ganglion cells cocultured with glial cells as compared with retinal ganglion cells cultured alone. After incubation under stress conditions for 72 

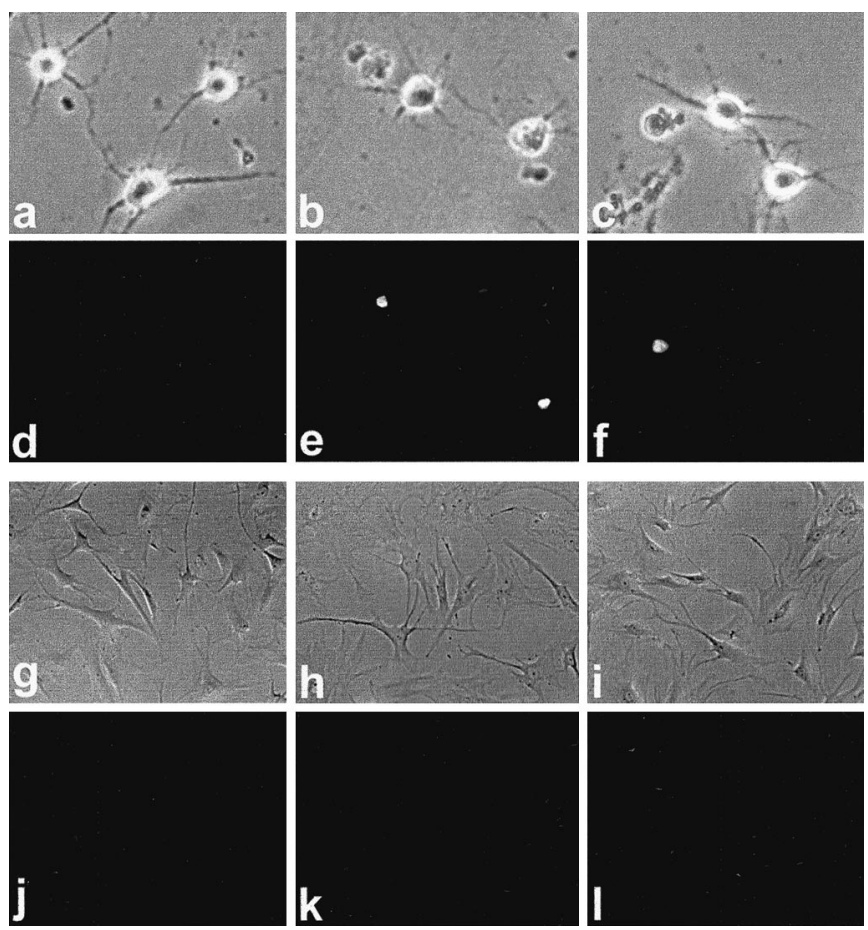

Figure 2. Morphological analysis of apoptotic cell death in cocultures of retinal ganglion cells and glial cells. $A-C$, Phase-contrast microscope images of retinal ganglion cells that were incubated under different conditions for 72 hr. $A$, Normal conditions. $B$, Simulated ischemia. $C$, Elevated hydrostatic pressure. Fluorescence microscope images of TUNEL in $D-F$ correspond to retinal ganglion cells seen in $A-C$, respectively. $G-I$, Phase-contrast microscope images of glial cells that were incubated under different conditions for 72 hr. $G$, Normal conditions. H, Simulated ischemia. I, Elevated hydrostatic pressure. Fluorescence microscope images of TUNEL in $J-L$ correspond to glial cells seen in $G-I$, respectively. After the incubation of cocultures under stress conditions, apoptosis was induced in retinal ganglion cells, although there was no evidence of apoptosis in glial cells.

hr, $>20 \%$ of the retinal ganglion exhibited positive TUNEL; in the retinal ganglion cells that were cultured alone the rate of positive TUNEL was $<7 \%$ (Mann-Whitney $U$ test; $p=0.006$ and $p=0.04$ for simulated ischemia and elevated hydrostatic pressure, respectively; Fig. $3 A$ ). In addition, after incubation under stress conditions apoptosis was induced in retinal ganglion cells in cocultures in a time-dependent manner (Fig. 3A). Although the rate of positive TUNEL was $24.10 \pm 6.0$ and $19.90 \pm 5.4 \%$ in retinal ganglion cells in cocultures that were exposed to simulated ischemia or elevated hydrostatic pressure for $72 \mathrm{hr}$, respectively, retinal ganglion cells in control cultures that were incubated under normal conditions exhibited apoptosis in $<2 \%$ of the cell population (Mann-Whitney $U$ test, $p=0.017, p=0.023$, respectively). However, the percentage of positive TUNEL was virtually absent in glial cells that were incubated in the absence or presence of stress conditions $(0.94 \pm$ 0.6 and $1.12 \pm 1.0 \%$, respectively; $p>0.05$ for both conditions).

In addition, we performed passive transfer experiments to examine the glial source of noxious insults on retinal ganglion cells. For this purpose, the conditioned medium of glial cells that were cultured alone was collected after their incubation in the presence or absence of simulated ischemia or elevated hydrostatic pressure for $72 \mathrm{hr}$. Retinal ganglion cells that were cultured alone then were incubated with the glial conditioned medium for $24 \mathrm{hr}$. The TUNEL was positive in $\sim 17 \%$ of retinal ganglion cells that were incubated with the conditioned medium of stressed glial cells, whereas $<2 \%$ of retinal ganglion cells exhibited positive TUNEL in cultures that were incubated with the conditioned medium of glial cells incubated under normal conditions (Mann-Whitney $U$ test; $p=0.04$ and $p=0.02$ for simulated ischemia and elevated hydrostatic pressure, respectively; Fig. $3 B$ ).

\section{Caspase activation accompanying retinal ganglion cell apoptosis}

To examine caspase activation, we used lysates of retinal cells in Western blotting. Western blot analysis demonstrated cleavage of caspase- 8 and caspase- 3 in retinal ganglion cells after exposure of the cocultures to simulated ischemia or elevated hydrostatic pressure. Western blots that used the lysates of retinal ganglion cells incubated under stress conditions revealed a $55 \mathrm{kDa}$ immunoreactive band corresponding to caspase- 8 and $\sim 30$ and $20 \mathrm{kDa}$ cleaved products. The presence of caspase- 3 activation was assessed by the observation of $17 \mathrm{kDa}$ subunit that was derived from the cleavage of the $32 \mathrm{kDa}$ pro-enzyme caspase- 3 . No cleavage of caspase- 8 or caspase- 3 was detected by using the lysates of glial cells that were incubated under stress conditions (Fig. 4A,B).

In addition, we examined caspase-3-like protease activity in cocultures. In situ examination that used the fluorogenic substrate Phiphilux-G6D2 demonstrated caspase-3-like activity in living retinal ganglion cells exposed to simulated ischemia or elevated hydrostatic pressure for $72 \mathrm{hr}$ (Fig. $4 \mathrm{C}-\mathrm{H}$ ). We also performed fluorometric analysis that used lysates of retinal ganglion cells to measure the cleavage of Ac-DEVD-AMC, which reflects caspase3-like activity. The amount of DEVD-AMC cleaving activity was $\sim 10$ times higher in retinal ganglion cells in cocultures that were incubated under simulated ischemia or elevated hydrostatic pressure for $72 \mathrm{hr}(38.67 \pm 7.4$ and $31.00 \pm 6.2 \mathrm{pmol} / \mathrm{mg}$ protein $/ \mathrm{min}$, respectively) compared with control cultures that were incubated under normal conditions $(3.50 \pm 1.1 \mathrm{pmol} / \mathrm{mg}$ protein $/ \mathrm{min}$; MannWhitney $U$ test; $p=0.006$ and $p=0.04$, respectively; Fig. $4 I$ ).

\section{Increased production of TNF- $\alpha$ and NO by glial cells in response to stressors}

We examined the possibility that the production of TNF- $\alpha$ and NOS by glial cells in cocultures exposed to stress conditions was involved directly in facilitating retinal ganglion cell apoptosis. Western blot analysis that used cell lysates revealed that the expression of TNF- $\alpha$ and iNOS was undetectable in retinal ganglion cells incubated under either normal or stress conditions. However, the expression of TNF- $\alpha$ and iNOS increased in glial cells in cocultures exposed to simulated ischemia or elevated hydrostatic pressure (Fig. 5A,B). Immunocytochemistry similarly demonstrated the increased expression of TNF- $\alpha$ and iNOS in glial cells in cocultures that were incubated under stress conditions (Fig. $5 C-H)$.

We measured the levels of TNF- $\alpha$ and the end products of NO in conditioned medium of the cocultures. TNF- $\alpha$ levels in the conditioned medium measured by ELISA were approximately eight times higher in cocultures that were exposed to simulated ischemia or elevated hydrostatic pressure as compared with cocultures that were incubated under normal conditions (Mann-Whitney $U$ test, $p=0.003$; Fig. $6 A$ ). As measured by a colorimetric assay, breakdown products of NO in conditioned medium increased approximately sevenfold in cocultures that were exposed to stress conditions compared with cocultures that were incubated under normal conditions ( $p=0.003$; Fig. $6 B$ ).

We also performed experiments in which cocultures were incubated under stress conditions in the presence of specific inhibitors of TNF- $\alpha$ or iNOS. Our experiments revealed that inhibitors of TNF- $\alpha$ or iNOS were able to diminish apoptotic cell death in retinal ganglion cells induced by simulated ischemia or elevated hydrostatic pressure. Inhibition of the bioactivity of TNF- $\alpha$ by a specific neutralizing antibody (AF510NA; $10 \mu \mathrm{g} / \mathrm{ml}$ ) resulted in a decreased rate of positive TUNEL from 24 to $8 \%(67 \%)$ in cocultures that were incubated under simulated ischemia and from 20 to $5 \%(75 \%)$ in cocultures that were incubated under elevated hydrostatic pressure (Mann-Whitney $U$ test; $p=0.0002$ ). Treatment of cocultures with $2.5 \mu \mathrm{M}$ of the selective inhibitor of iNOS, $1400 \mathrm{~W}$, decreased the rate of positive TUNEL $\sim 50 \%$ in cocultures that were incubated under simulated ischemia and $\sim 35 \%$ in cocultures that were incubated under elevated hydrostatic pressure $(p=$ 0.003; Fig. 7). Inhibition of apoptosis by a neutralizing antibody 



a

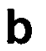

b

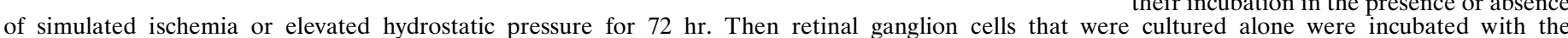

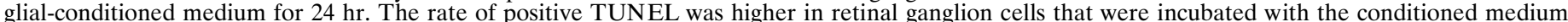

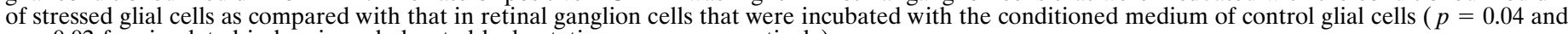
$p=0.02$ for simulated ischemia and elevated hydrostatic pressure, respectively).

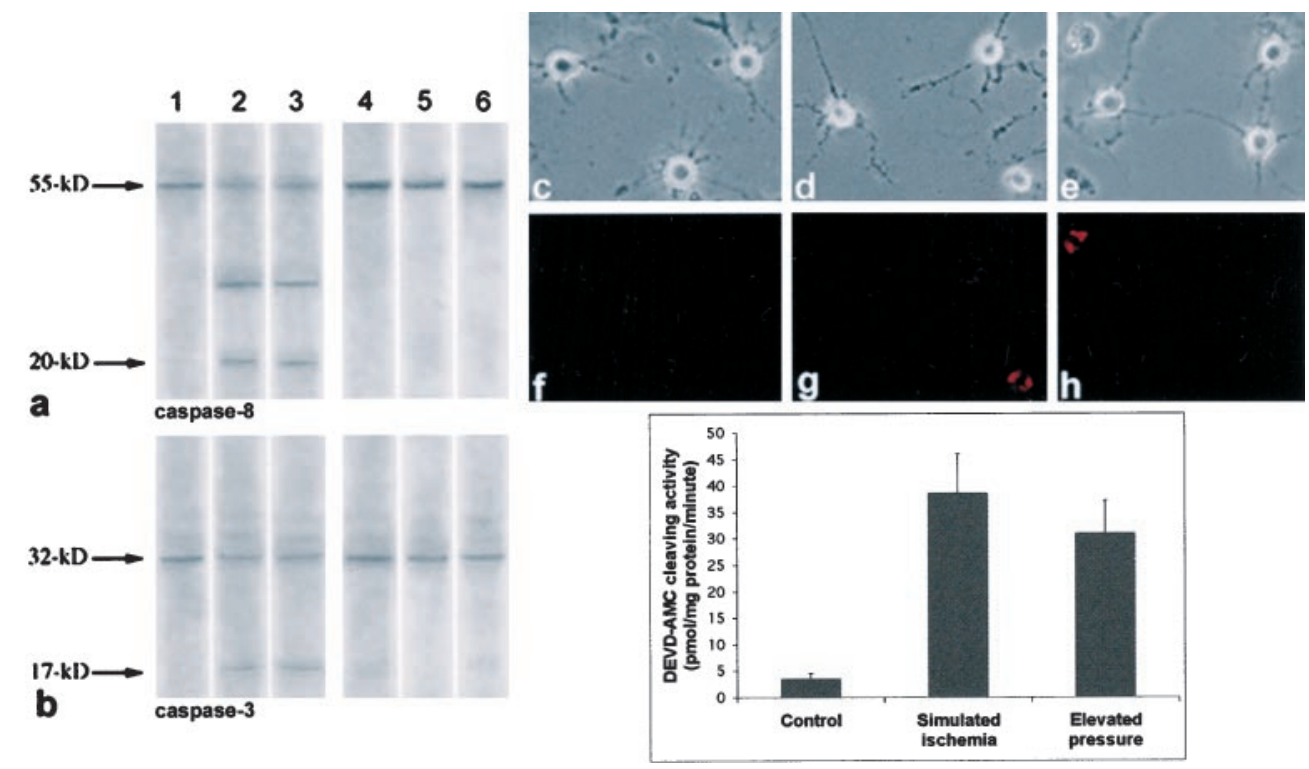

Figure 4. Examination of caspase activity in cocultures incubated under simulated ischemia or elevated hydrostatic pressure. $A$, Western blot analysis of caspase- 8 expression in cocultures. $B$, Western blot analysis of caspase-3 expression cocultures. Column 1, Control retinal ganglion cells; column 2, retinal ganglion cells incubated under simulated ischemia for $72 \mathrm{hr}$; column 3, retinal ganglion cells incubated under elevated hydrostatic pressure for $72 \mathrm{hr}$; column 4, control glial cells; column 5, glial cells incubated under simulated ischemia for $72 \mathrm{hr}$; column 6, glial cells incubated under elevated hydrostatic pressure for 72 hr. Western blots revealed that the $55 \mathrm{kDa}$ immunoreactive band corresponding to caspase- 8 cleaved to 30 and $20 \mathrm{kDa}$ products in retinal ganglion cells that were incubated under stress conditions. In addition, $32 \mathrm{kDa}$ pro-enzyme caspase- 3 cleaved to a $17 \mathrm{kDa}$ active subunit in retinal ganglion cells. No cleavage of caspase- 8 or caspase- 3 was detected with the use of the extracts of glial cells. Caspase activation also was examined, in situ, using Phiphilux$\mathrm{G}_{6} \mathrm{D}_{2}$ in retinal ganglion cells that were incubated under different conditions for 72 hr. $C$, Normal conditions. $D$, Simulated ischemia. $E$, Elevated hydrostatic pressure. Fluorescence microscope images seen in $F-H$ correspond to phase-contrast images of the retinal ganglion cells seen in $C-E$, respectively. Rhodamine fluorescence $(\mathrm{red})$ indicates caspase-3-like activity in retinal ganglion cells that were incubated under stress conditions. I, The amount of DEVD-AMC cleaving activity with the use of fluorometric analysis was higher in retinal ganglion cells in cocultures that were incubated under simulated ischemia or elevated hydrostatic pressure for $72 \mathrm{hr}$ as compared with cocultures that were incubated under normal conditions (Mann-Whitney $U$ test; $p=0.006$ and $p=0.04$, respectively).

against TNF- $\alpha$ was more prominent than that by $1400 \mathrm{~W}$ ( $p=$ 0.008).

\section{DISCUSSION}

Both elevated intraocular pressure and ischemia are common stress factors identified in glaucomatous eyes that are thought to affect retinal ganglion cell survival adversely (Hart et al., 1979; Quigley et al., 1980; Hayreh, 1985). However, the pathophysiological mechanisms by which elevated intraocular pressure leads to neuronal damage in glaucoma are unknown. The blockade of axoplasmic flow at the lamina cribrosa in the optic nerve head and thereby the blockage of neurotrophin transport to the retinal ganglion cells (Anderson and Hendrickson, 1974; Minckler et al., 1976; Quigley and Addicks, 1980; Pease et al., 2000) as well as ischemia secondary to elevated intraocular pressure (Hayreh, 1985; Flammer, 1994; Chung et al., 1999) have been suggested to be two mechanisms contributing to retinal ganglion cell death in glaucoma.

Although some evidence indicates that apoptotic cell death can be triggered by elevated hydrostatic pressure itself, as shown in human lymphoblasts (Takano et al., 1997), studies on the direct effect of elevated pressure on neuronal survival are limited [Agar A, Hill M, Coroneo MT (1999). Abstract. Invest Ophthalmol Vis Sci. 40:A265]. Our experiments provide evidence that environmental stress created by elevated hydrostatic pressure as well as simulated ischemia could affect neuronal survival. These findings are in accordance with previous observations that different cells exposed to biomechanical forces, including elevated hydrostatic pressure, exhibit functional as well as morphological changes. For example, hydrostatic pressure induces cytokine expression in a chondrocytelike cell line, which includes TNF- $\alpha$ (Takahashi et al., 1998). In the eye, human lamina cribrosa astrocytes have been shown to react to pressure changes in their environment by modulating the production and secretion of extracellular matrix macromolecules (Hernandez and Pena, 1997). In addition, recent evidence suggests that cell lines derived from several intraocular tissues, including retinal cells and optic nerve head astrocytes, respond to acute and sus- 


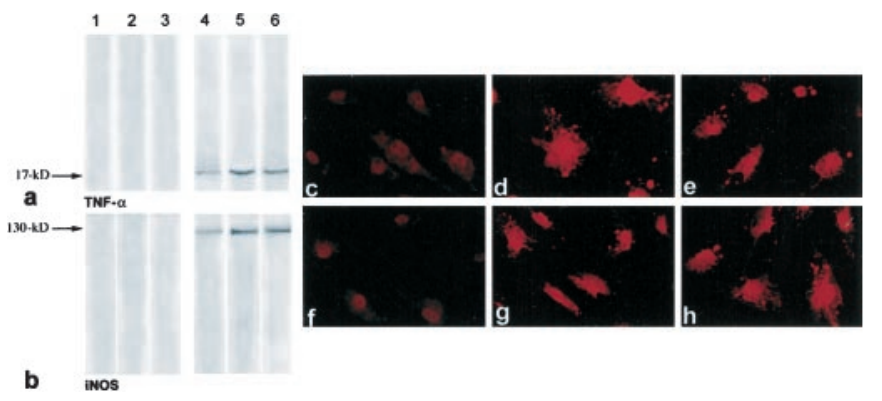

Figure 5. Examination of TNF- $\alpha$ and iNOS expression in cocultures that were incubated under simulated ischemia or elevated hydrostatic pressure. Both Western blot analysis $(A, B)$ and immunocytochemistry $(C-H)$ revealed increased expression of TNF- $\alpha$ and iNOS in glial cells, but not in retinal ganglion cells, in cocultures that were incubated under stress conditions. $A$, Western blot analysis of TNF- $\alpha$ expression. $B$, Western blot analysis of iNOS expression. Column 1, Control retinal ganglion cells; column 2, retinal ganglion cells that were incubated under simulated ischemia for $72 \mathrm{hr}$; column 3, retinal ganglion cells that were incubated under elevated hydrostatic pressure for $72 \mathrm{hr}$; column 4, control glial cells; column 5 , glial cells that were incubated under simulated ischemia for $72 \mathrm{hr}$; column 6 , glial cells that were incubated under elevated hydrostatic pressure for 72 hr. $C-E, \mathrm{TNF}-\alpha$ expression in glial cells that were incubated under different conditions for $72 \mathrm{hr}$. $C$, Normal conditions. $D$, Simulated ischemia. $E$, Elevated hydrostatic pressure. $F-H$, iNOS expression in glial cells that were incubated under different conditions for $72 \mathrm{hr}$. $F$, Normal conditions. $G$, Simulated ischemia. $H$, Elevated hydrostatic pressure.

tained levels of elevated hydrostatic pressure by changing their cell morphology as well as by increasing basal adenylyl cyclase activity (Wax et al., 2000).

In the current study, cell survival was examined in primary cocultures of retinal ganglion cells and glial cells that had been exposed to elevated hydrostatic pressure for a longer period (up to $72 \mathrm{hr}$ ), and it was demonstrated that the elevated hydrostatic pressure decreased neuronal survival. Increased production of apoptosis-promoting substances by retinal glial cells after exposure to elevated hydrostatic pressure or simulated ischemia accounts, in part, for the increased rate of cell death in cocultured retinal ganglion cells. Passive transfer experiments confirmed that the source of noxious insults on retinal ganglion cells was retinal glial cells that had been exposed to stress conditions. We therefore propose that alterations in the cellular functions of glial cells in the presence of environmental stress created during the course of glaucomatous optic neuropathy in vivo may lead to retinal ganglion cell death in these eyes. Reactivated glial cells in the outer retina have been implicated similarly in the ensuing death of photoreceptor cells (Cotinet et al., 1997; de Kozak et al., 1997; Goureau et al., 1999). Here, we focused on TNF- $\alpha$ and NO among several soluble factors secreted by stressed glial cells on the basis of findings obtained from glaucomatous eyes (Neufeld et al., 1997; Yan et al., 2000).

Tumor necrosis factor- $\alpha$ is known as a potent immunomediator and proinflammatory cytokine that is upregulated rapidly in the brain after injury (Liu et al., 1994; Barone et al., 1997). TNF- $\alpha$ is produced by reactivated macrophages, astrocytes, microglia, and retinal glial cells (Lieberman et al., 1989; Semenzato, 1990; Bren-

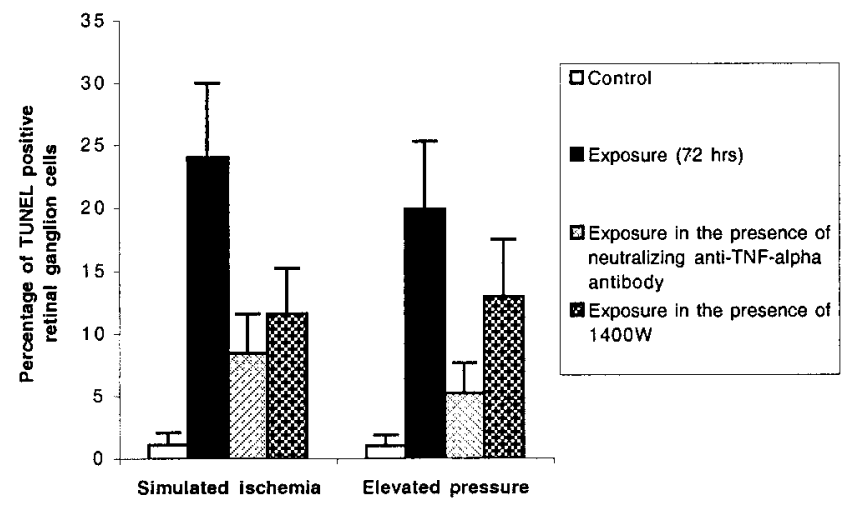

Figure 7. Inhibition of apoptosis in retinal ganglion cells in cocultures that were incubated under stress conditions in the presence of specific inhibitors of TNF- $\alpha$ or iNOS. Treatment of cocultures with a specific antibody neutralizing the activity of TNF- $\alpha(10 \mu \mathrm{g} / \mathrm{ml})$ or with a selective inhibitor of iNOS, $1400 \mathrm{~W}(2.5 \mu \mathrm{M})$, decreased the rate of positive TUNEL after incubation under stress conditions (Mann-Whitney $U$ test; $p=0.0002$ and $p=0.003$, respectively). Inhibition of apoptosis by a neutralizing antibody against TNF- $\alpha$ was more prominent than that by $1400 \mathrm{~W}(p=0.008)$.

ner et al., 1993; de Kozak et al., Meda et al., 1995; Cotinet et al., 1997). The dramatic increase in TNF- $\alpha$ production after ischemic and excitotoxic brain injury suggests an important role for this cytokine in modifying the neurodegenerative process. TNF- $\alpha$ also is known to be a potent activator of neurotoxic substances such as NO and excitotoxins (McGeer et al., 1993; Rothwell and Hopkins, 1995; Martin-Villalba et al., 1999). Its excessive synthesis after trauma has been correlated with poor outcome (Ertel et al., 1995), and its inhibition is accompanied by reduced brain damage (Shohami et al., 1996). In addition, a new concept in neurodegeneration exclaims that picogram concentrations of TNF- $\alpha$, which is known to be noncytotoxic, induces cell death via the "silencing of survival signals" (Venters et al., 2000). Regarding optic nerve, TNF- $\alpha$ has been thought to account for axonal degeneration and glial changes that have been observed in the optic nerves of patients with AIDS (Lin et al., 1997). Furthermore, intravitreal injections of TNF- $\alpha$ into rabbit eyes produced axonal degeneration in their optic nerves (Madigan et al., 1996). Because our cultures were depleted of microglia, astrocytes and retinal Müller glial cells appeared to be the likely sources of TNF- $\alpha$ secreted into the conditioned medium. $\mathrm{TNF}-\alpha$ released by chemically reactivated glial cells has been implicated similarly in the increased rate of apoptosis in cocultured neurons (Viviani et al., 1998; Downen et al., 1999).

Tumor necrosis factor- $\alpha$ is an inducer of apoptotic cell death via TNF- $\alpha$ receptor-1 occupancy in a caspase-mediated pathway, which includes the activation of caspase-8 (Hsu et al., 1995). Our observation of caspase- 8 activation suggests the involvement of TNF- $\alpha$ as a mediator of the apoptosis of retinal ganglion cells. Furthermore, it has been demonstrated recently that the expression of TNF- $\alpha$ and its receptor are increased in glaucomatous optic nerve head. Although the TNF- $\alpha$ is expressed mostly in astroglial cells, the expression of TNF- $\alpha$ receptor- 1 is more prominent in nerve bundles located in the anterior region of the glaucomatous
Figure 6. Measurement of TNF- $\alpha$ and end products of NO in conditioned medium of cocultures that were incubated under stress conditions. $A$, Titers of TNF- $\alpha$ in conditioned medium as measured by ELISA. $B$, Titers of end products of NO in conditioned medium as measured by a colorimetric assay. Levels of both TNF- $\alpha$ and $\mathrm{NO}$ end products were higher in the conditioned medium of cocultures that were exposed to simulated ischemia or elevated hydrostatic pressure as compared with cocultures that were incubated under normal conditions (Mann-Whitney $U$ test; $p=0.003$ and $p=$ 0.003 , respectively).
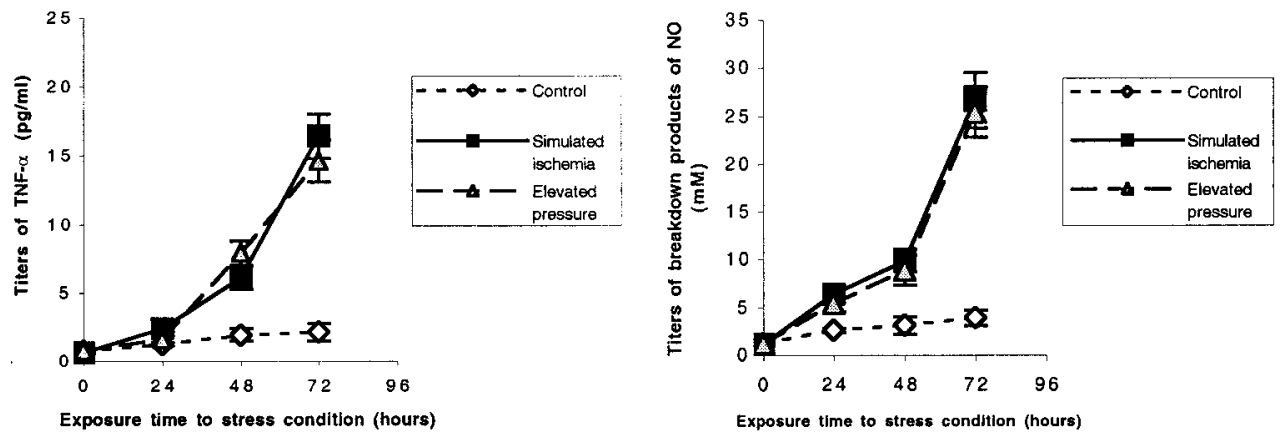
optic nerve head (Yan et al., 2000). These observations support our current findings that retinal neuronal tissue is an important target for the effects of TNF- $\alpha$ that are produced by glial cells.

In addition to TNF- $\alpha$, we found that increased production of NO in retinal glial cells that have been exposed to different stress conditions induced cell death in cocultured retinal ganglion cells. Previous studies suggested that glial expression of iNOS caused delayed neurotoxicity in mixed cultures of cortical neuronal and glial cells (Dawson et al., 1994). Similar to TNF- $\alpha$, NO, which is formed from L-arginine by NOS, has been implicated in several neurodegenerative diseases. Although two isoforms, neuronal NOS and endothelial NOS, are expressed constitutively, iNOS is induced after infection and trauma (Bredt and Snyder, 1994). Induction of NOS in brain tissue results in neuronal cell death (Iadecola et al., 1995) in which astrocytes and microglia are major sources of the iNOS production (Liu et al., 1996). Inducible NOS produced by glial cells also is thought to cause retinal neuronal cell death in different retinal diseases and after optic nerve axotomy (Cotinet et al., 1997; de Kozak et al., 1997; Koeberle and Ball, 1999). In addition, intravitreal injection of the NO donor has been shown to cause retinal ganglion cell and photoreceptor loss, whereas reduction of NO levels by systemic inhibition of NOS reduces retinal ganglion cell loss in a rat model of retinal ischemia (Lam and Tso, 1996). Nitric oxide also has been suggested to play a role in the neurodegeneration process in glaucoma (Neufeld et al., 1997, 1999).

Our experiments that used inhibitors of TNF- $\alpha$ or iNOS revealed an inhibition of apoptotic cell death in retinal ganglion cells in cocultures that had been exposed to simulated ischemia or elevated hydrostatic pressure. Although iNOS inhibition provided partial protection against apoptotic cell death in cocultures, a more prominent inhibition of apoptosis was observed after the inhibition of TNF- $\alpha$. These results indicate a crucial role for endogenous $\mathrm{TNF}-\alpha$ in mediating neurotoxicity in cultured retinal ganglion cells. Because TNF- $\alpha$ induces NO secretion (Goureau et al., 1997; Shafer and Murphy, 1997; Heneka et al., 1998), inhibition of its activity indirectly could decrease the harmful effect created by NO as well. Similar to our observations, neutralizing anti-TNF- $\alpha$ antiserum, rather than a NOS inhibitor, inhibited neurotoxicity of cytokine-induced production of iNOS and TNF- $\alpha$ in neuronastrocyte cultures that were derived from human fetal cerebrum (Downen et al., 1999). Furthermore, the inhibition of TNF- $\alpha$ has been shown to reduce iNOS expression and NOS activity (Perkins et al., 1998). In addition, in vivo observations support the idea that neutralization of systemic TNF- $\alpha$ ameliorates target organ damage in brain ischemia or in experimental autoimmune uveoretinitis (Dick et al., 1996; Sartani et al., 1996; Barone et al., 1997; Lavine et al., 1998). However, selective inhibition of iNOS does not prevent the organ injury/dysfunction that is caused by endotoxin (Wray et al., 1998). These findings emphasize the importance of further research to determine the potential neuroprotective role of TNF- $\alpha$ or iNOS inhibition in stressed retinal ganglion cells under in vivo conditions, as occurs in glaucoma, and to identify strategies that are feasible for patient treatment.

In conclusion, our findings provide evidence that the functional state of glial cells determined by environmental factors may be important for determining the ultimate role of glial cells as either neuroprotective or neurotoxic. The retinal glial cells exposed to stress conditions similar to that created in vivo during the process of glaucoma, such as elevated hydrostatic pressure or simulated ischemia, have a neurotoxic influence on retinal ganglion cells. Because of increased production of death-promoting substances, including TNF- $\alpha$, alterations in the functional state of glial cells in response to these stressors lead to retinal ganglion cell death. These findings reveal a novel pathogenic mechanism for retinal ganglion cell death in glaucoma and provide a novel therapeutic target for neuroprotection in the treatment of glaucomatous optic neuropathy.

\section{REFERENCES}

Anderson DR, Hendrickson A (1974) Effect of intraocular pressure on rapid axoplasmic transport in monkey optic nerve. Invest Ophthalmol Vis Sci 13:771-783.

Barone FC, Arvin B, White RF, Miller A, Webb CL, Willette RN, Lysko PG, Feuerstein GZ (1997) Tumor necrosis factor- $\alpha$. A mediator of focal ischemic brain injury. Stroke 28:1233-1244.

Barres BA, Silverstein BE, Corey DP, Chun LLY (1988) Immunological, morphological, and electrophysiological variation among retinal ganglion cells purified by panning. Neuron 1:791-803.

Bredt DS, Snyder SH (1994) Nitric oxide: a physiologic messenger molecule. Annu Rev Biochem 63:175-195.

Brenner T, Yamin A, Abramsky O, Gallily R (1993) Stimulation of tumor necrosis factor- $\alpha$ production by mycoplasma and inhibition by dexamethasone in cultured astrocytes. Brain Res 608:273-279.

Brewer GJ, Torricelli JR, Evege EK, Price PJ (1993) Optimized survival of hippocampal neurons in B27-supplemented Neurobasal, a new serumfree medium combination. J Neurosci Res 35:567-576.

Cheng Y, Deshmukh M, D'Costa A, Demaro JA, Gidday JM, Shah A, Sun Y, Jacquin MF, Johnson EM, Holtzman DM (1998) Caspase inhibitor affords neuroprotection with delayed administration in a rat model of neonatal hypoxic-ischemic brain injury. J Clin Invest 101:1992-1999.

Chung HS, Harris A, Evans DW, Kagemann L, Garzozi HJ, Martin B (1999) Vascular aspects in the pathophysiology of glaucomatous optic neuropathy. Surv Ophthalmol 43[Suppl 1]:S43-S50.

Cotinet A, Goureau O, Hicks D, Thillaye-Goldenberg B, de Kozak Y (1997) Tumor necrosis factor and nitric oxide production by retinal M fller glial cells from rats exhibiting inherited retinal dystrophy. Glia 20:59-69.

Dawson VL, Brahmbhatt HP, Mong JA, Dawson TM (1994) Expression of inducible nitric oxide synthase causes delayed neurotoxicity in primary mixed neuronal-glial cortical cultures. Neuropharmacology 33:1425-1430.

de Kozak Y, Cotinet A, Goureau O, Hicks D, Thillaye-Goldenberg B (1997) Tumor necrosis factor and nitric oxide production by resident retinal glial cells from rats presenting hereditary retinal degeneration. Ocul Immunol Inflamm 5:85-94.

Dick AD, McMenamin PG, Korner H, Scallon BJ, Ghrayeb J, Forrester JV, Sedgwick JD (1996) Inhibition of tumor necrosis factor activity minimizes target organ damage in experimental autoimmune uveoretinitis despite quantitatively normal activated T-cell traffic to the retina. Eur J Immunol 26:1018-1025.

Downen M, Amaral TD, Hua LL, Zhao M-L, Lee SC (1999) Neuronal death in cytokine-activated primary human brain cell culture: role of tumor necrosis factor- $\alpha$. Glia 28:114-127.

Dugan LL, Bruno VMG, Amagasu SM, Giffard RG (1995) Glia modulate the response of murine cortical neurons to excitotoxicity: glia exacerbate AMPA neurotoxicity. J Neurosci 15:4545-4555.

Ertel W, Keel M, Bonaccio M, Steckholzer U, Gallati H, Kenney JS, Trentz O (1995) Release of anti-inflammatory mediators after mechanical trauma correlates with severity of injury and clinical outcome. J Trauma 39:879-885.

Finucane DM, Bossy-Wetzel E, Waterhouse NJ, Cotter TG, Green DR (1999) Bax-induced caspase activation and apoptosis via cytochrome $c$ release from mitochondria is inhibitable by Bcl-xL. J Biol Chem 274:2225-2233.

Flammer J (1994) The vascular concept of glaucoma. Surv Ophthalmol [Suppl] 38:S3-S6.

Garvey EP, Oplinger JA, Furfine ES, Kiff RJ, Laszlo F, Whittle BJ, Knowles RG (1997) 1400W is a slow, tight-binding and highly selective inhibitor of inducible nitric oxide synthase in vitro and in vivo. J Biol Chem 272:4959-4963.

Gavrieli Y, Sherman Y, Ben-Sasson SA (1992) Identification of programmed cell death in situ via specific labeling of nuclear DNA fragmentation. J Cell Biol 119:493-501.

Goureau O, Amiot F, Dautry F, Courtois Y (1997) Control of nitric oxide production by endogenous TNF- $\alpha$ in mouse retinal pigmented epithelial and MSller glial cells. Biochem Biophys Res Commun 240:132-135.

Goureau O, Regnier-Ricard F, Courtois Y (1999) Requirement for nitric oxide in retinal neuronal cell death induced by activated MSller glial cells. J Neurochem 72:2506-2515.

Hart Jr WM, Yablonski M, Kass MA, Becker B (1979) Multivariate analysis of the risk of glaucomatous visual field loss. Arch Ophthalmol 97:1455-1458

Haugland RP, Larison KD (1994) Handbook of fluorescent probes and research chemicals, 5th ed, pp 172-180. Eugene, OR: Molecular Probes.

Hayreh SS (1985) Inter-individual variation in blood supply of the optic nerve head. Its importance in various ischemic disorders of the optic nerve head, and glaucoma, low-tension glaucoma, and allied disorders. Doc Ophthalmol 59:217-2466.

Heneka MT, Loschmann PA, Gleichmann M, Weller M, Schulz JB, Wullner U, Klockgether T (1998) Induction of nitric oxide synthase nitric oxide-mediated apoptosis in neuronal PC12 cells after stimulation with tumor necrosis factor- $\alpha /$ lipopolysaccharide. J Neurochem 71:88-94.

Hernandez MR, Pena JD (1997) The optic nerve head in glaucomatous optic neuropathy. Arch Ophthalmol 115:389-395.

Hewett SJ, Csernansky CA, Choi DW (1994) Selective potentiation of 
NMDA-induced neuronal injury following induction of astrocytic iNOS. Neuron 13:487-494.

Hsu H, Xiong J, Goeddel DV (1995) The TNF receptor 1-associated protein TRADD signals cell death and NF- $\kappa \mathrm{B}$ activation. Cell 81:495-504.

Iadecola C, Zhang F, Xu X (1995) Inhibition of inducible nitric oxide synthase ameliorates cerebral ischemic damage. Am J Physiol 268:R286-R292.

Jo SA, Wang E, Benowitz LI (1999) Ciliary neurotrophic factor is an axogenesis factor for retinal ganglion cells. Neuroscience 89:579-591.

Koeberle PD, Ball AK (1999) Nitric oxide synthase inhibition delays axonal degeneration and promotes the survival of axotomized retinal ganglion cells. Exp Neurol 158:366-381.

Lam T, Tso M (1996) Nitric oxide synthase (NOS) inhibitors ameliorate retinal damage induced by ischemia in rats. Res Commun Mol Pathol Pharmacol 92:329-340.

Lavine SD, Hofman FM, Zlokovic BV (1998) Circulating antibody against tumor necrosis factor- $\alpha$ protects rat brain from reperfusion injury. J Cereb Blood Flow Metab 18:52-58.

Lieberman AP, Pitha PM, Shin HS, Shin ML (1989) Production of tumor necrosis factor and other cytokines by astrocytes stimulated with lipopolysaccharide or a neurotropic virus. Proc Natl Acad Sci USA 86:6348-6352.

Lin XH, Kashima Y, Khan M, Heller KB, Gu XZ, Sadun AA (1997) An immunohistochemical study of TNF- $\alpha$ in optic nerves from AIDS patients. Curr Eye Res 16:1064-1068.

Liu J, Zhao M-L, Brosnan CF, Lee SC (1996) Expression of type II nitric oxide synthase in primary human astrocytes and microglia: role of IL-1 $\beta$ and IL-1 receptor antagonist. J Immunol 157:3569-3576.

Liu T, Clark RK, McDonnell PC, Young PR, White RF, Barone FC, Feuerstein GZ (1994) Tumor necrosis factor- $\alpha$ expression in ischemic neurons. Stroke 25:1481-1488.

Madigan MC, Sadun AA, Rao NS, Dugel PU, Tenhula WN, Gill PS (1996) Tumor necrosis factor- $\alpha$ (TNF- $\alpha$ )-induced optic neuropathy in rabbits. Neurol Res 18:176-184.

Martin-Villalba A, Herr I, Jeremias I, Hahne M, Brandt R, Vogel J, Schenkel J, Herdegen T, Debatin KM (1999) CD95 ligand (Fas-L/APO$1 \mathrm{~L}$ ) and tumor necrosis factor-related apoptosis-inducing ligand mediate ischemia-induced apoptosis in neurons. J Neurosci 19:3809-3817.

McGeer PL, Kawamata T, Walker DG, Akiyama H, Tooyama I, McGeer EG (1993) Microglia in degenerative neurological disease. Glia 7:84-92.

Meda L, Cassatella MA, Szendrei GI, Otvos Jr L, Baron P, Villalba M, Ferrari D, Rossi F (1995) Activation of microglial cells by $\beta$-amyloid protein interferon- $\gamma$. Nature 374:647-650.

Minckler DS, Tso MO, Zimmerman LE (1976) A light microscopic, autoradiographic study of axoplasmic transport in the optic nerve head during ocular hypotony, increased intraocular pressure, and papilledema. Am J Ophthalmol 82:741-757.

Neufeld AH, Hernandez MR, Gonzalez M (1997) Nitric oxide synthase in the human glaucomatous optic nerve head. Arch Ophthalmol 115:497-503.

Neufeld AH, Sawada S, Becker B (1999) Inhibition of nitric oxide synthase-2 by aminoguanidine provides neuroprotection of retinal ganglion cells in a rat model of glaucoma. Proc Natl Acad Sci USA 96:9944-9948.

Pease ME, McKinnon SJ, Quigley HA, Kerrigan-Baumrind LA, Zack DJ (2000) Obstructed axonal transport of BDNF and its receptor TrkB in experimental glaucoma. Invest Ophthalmol Vis Sci 41:764-774.

Perkins DJ, St. Clair EW, Misukonis MA, Weinberg JB (1998) Reduction of NOS2 overexpression in rheumatoid arthritis patients with anti-tumor necrosis factor- $\alpha$ monoclonal antibody (cA2). Arthritis Rheum 41:2205-2210.
Quigley HA, Addicks EM (1980) Chronic experimental glaucoma in primates. II. Effect of extended intraocular pressure elevation on optic nerve head and axonal transport. Invest Ophthalmol Vis Sci 19:137-152.

Quigley HA, Nickells RW, Kerrigan LA, Pease ME, Thibault DJ, Zack DJ (1995) Retinal ganglion cell death in experimental glaucoma and after axotomy occurs by apoptosis. Invest Ophthalmol Vis Sci 36:774-786.

Raivich G, Bohatschek M, Kloss CU, Werner A, Jones LL, Kreutzberg GW (1999) Neuroglial activation repertoire in the injured brain: graded response, molecular mechanisms, and cues to physiological function. Brain Res Rev 30:77-105.

Ridet JL, Malhotra SK, Privat A, Gage FH (1997) Reactive astrocytes: cellular and molecular cues to biological function. Trends Neurosci 20:570-577.

Rothwell NJ, Hopkins SJ (1995) Cytokines and the nervous system. II. Actions and mechanisms of action. Trends Neurosci 18:130-136.

Sartani G, Silver PB, Rizzo LV, Chan CC, Wiggert B, Mastorakos G, Caspi RR (1996) Anti-tumor necrosis factor- $\alpha$ therapy suppresses the induction of experimental uveoretinitis in mice by inhibiting antigen priming. Invest Ophthalmol Vis Sci 37:2211-2218.

Selles-Navarro I, Villegas-Perez MP, Salvador-Silva M, Ruiz-Gomez JM, Vidal-Sanz M (1996) Retinal ganglion cell death after different transient periods of pressure-induced ischemia survival intervals. Invest Ophthalmol Vis Sci 37:2002-2014.

Semenzato G (1990) Tumor necrosis factor: a cytokine with multiple biological activity. Br J Cancer 61:354-361.

Shafer RA, Murphy S (1997) Activated astrocytes induce nitric oxide synthase-2 in cerebral endothelium via tumor necrosis facto- $\alpha$. Glia 21:370-379.

Shohami E, Bass R, Wallach D, Yamin A, Gallily R (1996) Inhibition of tumor necrosis- $\alpha$ (TNF- $\alpha$ ) activity in rat brain is associated with cerebroprotection after closed head injury. J Cereb Blood Flow Metab 16:378-384.

Takahashi K, Kubo T, Arai Y, Kitajima I, Takigawa M, Imanishi J, Hirasawa Y (1998) Hydrostatic pressure induces expression of interleukin-6 tumor necrosis factor- $\alpha$ mRNA in a chondrocyte-like cell line. Ann Rheum Dis 57:231-236.

Takano KJ, Takano T, Yamanouchi Y, Satau T (1997) Pressure-induced apoptosis in human lymphoblasts. Exp Cell Res 235:155-160.

Tezel G, Wax MB (1999) Inhibition of caspase activity in retinal cell apoptosis induced by various stimuli in vitro. Invest Ophthalmol Vis Sci 40:2660-2667.

Tezel G, Seigel GM, Wax MB (1999) Density-dependent resistance to apoptosis in retinal cells. Curr Eye Res 19:377-388.

Vandenberghe W, Bosch LVD, Robberecht W (1998) Glial cells potentiate kainate-induced neuronal death in a motoneuron-enriched spinal coculture system. Brain Res 807:1-10.

Venters HD, Dantzer R, Kelley KW (2000) A new concept in neurodegeneration: TNF- $\alpha$ is a silencer of survival signals. Trends Neurosci 23:175-180.

Viviani B, Corsini E, Galli CL, Marinovich M (1998) Glia increase degeneration of hippocampal neurons through release of tumor necrosis factor- $\alpha$. Toxicol Appl Pharmacol 150:271-276.

Wax MB, Tezel G, Kobayashi S, Hernandez MR (2000) Responses of different cell lines from ocular tissues to elevated hydrostatic pressure. Br J Ophthalmol 84:423-428.

Wray GM, Millar CG, Hinds CJ, Thiemermann C (1998) Selective inhibition of the activity of inducible nitric oxide synthase prevents the circulatory failure, but not the organ injury/dysfunction, caused by endotoxin. Shock 9:329-335.

Yan X, Tezel G, Edward DP, Wax MB (2000) Matrix metalloproteinases and tumor necrosis factor- $\alpha$ in glaucomatous optic nerve head. Arch Ophthalmol 118:666-673. 